\title{
Wheat straw hemicelluloses added with cellulose nanocrystals and citric acid. Effect on film physical properties
}

\author{
Paulo H.F. Pereira ${ }^{a}$, Keith W. Waldron ${ }^{b}$, David R. Wilson ${ }^{b}$, Arcelina P. Cunha ${ }^{c}$, \\ Edy S. de Brito $^{\mathrm{d}}$, Tigressa H.S. Rodrigues ${ }^{\mathrm{d}}$, Morsyleide F. Rosa ${ }^{\mathrm{d}}$, Henriette M.C. Azeredo ${ }^{\mathrm{d}, *}$
}

\author{
a Faculty of Engeneering of Guaratinguetá, São Paulo State University, Av. Ariberto Pereira da Cunha, 333, Guaratingueta, SP, 12516-410, Brazil \\ b Institute of Food Research, Norwich Research Park, Colney, Norwich, NR4 7UA, UK \\ ${ }^{\mathrm{c}}$ Federal University of Ceara, Campus Pici, 60440-900, Fortaleza, CE, Brazil \\ d Embrapa Tropical Agroindustry, R. Dra. Sara Mesquita, 2270, Fortaleza, CE, 60511-110, Brazil
}

\section{A R T I C L E I N F O}

\section{Article history:}

Received 21 November 2016

Received in revised form 1 February 2017

Accepted 4 February 2017

Available online 4 February 2017

\section{Keywords:}

Biodegradable films

Bionanocomposites

Crosslinking

Nanocellulose

Cellulose whiskers

\begin{abstract}
A B S T R A C T
Wheat straw has been used as a source of hemicelluloses (WSH) and cellulose nanocrystals (CNC) for the elaboration of biodegradable films. Different films have been formed by using WSH as a matrix and different contents of $\mathrm{CNC}$ and citric acid. The predominant hemicelluloses were arabinoxylans. CNC reinforced the films, improving tensile strength and modulus, water resistance and water vapor barrier. Citric acid, on the other hand, presented concomitant plasticizing and crosslinking effects (the latter also evidenced by FTIR), probably due to a crosslinking extension by glycerol. The use of $5.9 \mathrm{wt} \% \mathrm{CNC}$ and $30 \mathrm{wt} \%$ citric acid was defined as optimal conditions, resulting in minimum water sensitivity and permeability, while maintaining a good combination of tensile properties. Under those conditions, the films presented enhanced modulus, elongation, water resistance, and barrier to water vapor when compared to the control WSH film, and might be used for wrapping or coating a variety of foods.
\end{abstract}

(c) 2017 Elsevier Ltd. All rights reserved.

\section{Introduction}

The petroleum-derived polymers have been presented to the world in the early 20 th century as mediocre substitutes for natural materials such as silk and rubber, but have been engineered since then to become mainstream materials of low-cost and superior properties, accounting for the declining use of natural polymers. However, a transition from petrochemistry to bioeconomy, involving the renaissance of renewable polymers, is expected at the 21st century (Mülhaupt, 2013). The reasons for this shift are related to the non-renewability, the overall environmental impacts, and the lack of biodegradability of the petroleum-derived polymers. The modern polymer technology has been thus increasingly focused on green routes.

Biorefining may be defined as the sustainable processing of biomass into products and/or energy. The biorefinery concept embraces technologies able to separate biomass resources (such as food industry by-products) into their building classes of molecules

\footnotetext{
* Corresponding author.

E-mail address: henriette.azeredo@embrapa.br (H.M.C. Azeredo).
}

(such as polysaccharides, proteins, phenolic compounds, and triglycerides) which are then converted to value added products such as biomaterials and energy carriers in an integrated way so as to maximize the economic value of the biomass while reducing waste production (Cherubini, 2010; Thomsen, 2005).

The world wheat consumption for 2015/2016 was around 710 million tons (WASDE, 2016). Wheat straw, an abundant wheat coproduct which is treated mostly as waste, is a source of cell wall polysaccharides such as hemicelluloses (mainly xylans) and cellulose (Jacquemin et al., 2015). Considering that the production of $1 \mathrm{~kg}$ of wheat grain generates an average of $1.3 \mathrm{~kg}$ of straw (Montane, Farriol, Salvado, Jollez, \& Chornet, 1998), the world annual generation of wheat straw may be estimated as about 920 million tons. Although part of the wheat straw is already used (e.g. for animal feed and paper production), the majority is usually treated as waste, when it could instead be used to produce high-valued materials such as biodegradable films to be used as greener alternatives to conventional food packaging materials.

Biodegradable films have been produced from a variety of biopolymeric matrices, including polysaccharides. However, polysaccharide films have usually poor tensile properties, besides being highly permeable to water vapor and sensitive to water 
(because of the hydrophilic nature of polysaccharides). Cellulose nanocrystals (CNCs), which are needlelike crystals measuring $4-25 \mathrm{~nm}$ in diameter and $100-1000 \mathrm{~nm}$ in length (Jonoobi et al., 2015), have been reported to improve overall physical properties of polysaccharide films, especially tensile properties, due to the high strength and stiffness of individual nanocrystals (Cho \& Park, 2011) as well as to mechanical percolation yielded by hydrogen bonding interactions between CNCs (Favier et al., 1995). CNCs are usually extracted by chemical treatments such as acid hydrolysis, which may be preceded by pretreatments such as steam explosion in order to fractionate the lignocellulosic material into its biopolymer components (Abdul Khalil, Bhat, \& Yusra, 2012).

Another way to improve physical properties of polysaccharide films is by crosslinking, which consists of linking polymer chains by covalent or non-covalent bonds, forming three-dimensional networks with reduced mobility, which results in improved water resistance, and usually improved tensile and barrier properties (Balaguer, Gómez-Estaca, Gavara, \& Hernandez-Muñoz, 2011). Citric acid has been reported to crosslink polysaccharides (Bonilla, Talón, Atarés, Vargas, \& Chiralt, 2013; Olsson, Hedenqvist, Johansson, \& Järnström, 2013a), while non-bonded citric acid may also act as a film plasticizer (Chabrat, Abdillahi, Rouilly, \& Rigal, 2012; Ortega-Toro, Collazo-Bigliardi, Talens, \& Chiralt, 2016; Shi et al., 2007). The crosslinking mechanism of citric acid is ascribed to covalent di-ester linkages between hydroxyl groups of two different polysaccharide chains and two carboxyl groups of citric acid (Coma, Sebti, Pardon, Pichavant, \& Deschamps, 2003; Olsson et al., 2013a). The reaction is favored by curing the films at temperatures above $100^{\circ} \mathrm{C}$ (Dastidar \& Netravali, 2012; Olsson et al., 2013a, 2013b).

In a previous study from our group (Azeredo et al., 2015), citric acid was reported to improve water vapor barrier and water sensitivity of wheat straw hemicellulose films (suggesting a plasticizing effect), while the overall tensile properties of the films have been impaired by citric acid. In this study, both citric acid and cellulose nanocrystals (CNCs) have been used as additives to wheat straw hemicellulose films, in an attempt to combine crosslinking and reinforcing effects to improve not only the water resistance of the films but also their tensile properties.

\section{Materials and methods}

\subsection{Isolation and characterization of wheat straw hemicelluloses (WSH)}

Wheat straw was milled to $0.5 \mathrm{~mm}$ in a Retsch Brinkmann ZM1 centrifugal grinding mill (Retsch GmbH, Haan, Germany). $100 \mathrm{~g}$ milled straw were washed with $1 \mathrm{~L}$ ethylenediamine tetraacetic acid (EDTA) solution $(0.2 \%, \mathrm{w} / \mathrm{v})$ at $90^{\circ} \mathrm{C}$ for $1 \mathrm{~h}$, to remove water soluble components and to chelate $\mathrm{H}_{2} \mathrm{O}_{2}$ decomposing metals. The hemicelluloses were then extracted with an alkaline $\mathrm{H}_{2} \mathrm{O}_{2}$ solution ( $3 \% \mathrm{w} / \mathrm{v}, \mathrm{pH}$ adjusted to 12.5 with $\mathrm{KOH}$ ) for $16 \mathrm{~h}$ at $50^{\circ} \mathrm{C}$, conditions modified from those previously optimized by Fang, Sun, Salisbury, Fowler, \& Tomkinson, 1999. The supernatant from the subsequent centrifugation was vacuum filtered and had its $\mathrm{pH}$ adjusted to 5.0 with acetic acid. Ethanol was added to a concentration of $60 \mathrm{vol} \%$, the suspension was stirred for $30 \mathrm{~min}$, left for $16 \mathrm{~h}$ at $4{ }^{\circ} \mathrm{C}$, centrifuged, washed with ethanol $70 \mathrm{vol} \%$, centrifuged again, and left to dry at $24{ }^{\circ} \mathrm{C}$. The dried WSH were then milled to a fine powder (particle size, $0.25 \mathrm{~mm}$ ) by using a basic mill (A10, IKA GmbH, Germany).

The neutral sugar composition of WSH was determined by gas chromatography-flame ionization detection (GC-FID). A $10 \mathrm{mg}$ sample of WSH was hydrolyzed with trifluoroacetic acid $4 \mathrm{M}$ for $6 \mathrm{~h}$ at $100^{\circ} \mathrm{C}$. The hydrolyzed WSH and the monosaccharide standards were acetylated with acetic anhydride and piridin $(2: 1, v / v)$, and the alditol acetates were dissolved in chloroform. The analyses were conducted in a Shimadzu GC-2010 Plus (Shimadzu, Japan) with a VF5-MS column $(0.25 \mu \mathrm{m}, 0.25 \mathrm{~mm} \times 60 \mathrm{~m})$. The injected volume was $1 \mu \mathrm{L}$ with a 1:20 split ratio. Nitrogen was used as carrier gas, whose flow was $0.83 \mathrm{~mL} / \mathrm{min}$. The oven temperature was increased from 190 to $230^{\circ} \mathrm{C}$ at $4{ }^{\circ} \mathrm{C} \mathrm{min}^{-1}$, then it was held at $230^{\circ} \mathrm{C}$ for $12 \mathrm{~min}$. The peaks were identified by comparing retention times with those obtained by injections of pure standards.

The hemicellulose and $\alpha$-cellulose contents of milled wheat straw and the isolated WSH were determined (in triplicate) based on TAPPI T203cm-99 (TAPPI, 2009), and the lignin contents, according to TAPPI, 2004.

\subsection{Isolation of cellulose nanocrystals}

Chipped wheat straw ( $1 \mathrm{~kg}$ each run) was steam exploded at $210^{\circ} \mathrm{C}$ for $10 \mathrm{~min}$ using a Cambi ${ }^{\mathrm{TM}}$ Steam Explosion Pilot Plant (Cambi, Asker, Norway) with a sealed $30 \mathrm{~L}$ vessel. The contents of the heating chamber were then released into a cyclone (to separate biomass from steam), and the solids were deposited in a hopper with $6.6 \mathrm{~L}$ hot water. The heating chamber was then pressurized again twice to 2-3 bar in order to dislodge any residual material. The resulting steam-exploded slurry was collected, filtered through a $100 \mu \mathrm{m}$ nylon mesh, dried $\left(60^{\circ} \mathrm{C}, 24 \mathrm{~h}\right)$ and milled to $0.5 \mathrm{~mm}$.

The dried steam-exploded slurry was then submitted to acetosolv pulping and alkaline-peroxide bleaching, as described by Nascimento et al. (2014), with some modifications. It was cooked in an aqueous solution of $93 \mathrm{wt} \%$ acetic acid and $0.3 \mathrm{wt} \% \mathrm{HCl}$, at a $1: 10$ ratio (w/v slurry: solution), under reflux at $110^{\circ} \mathrm{C}$ for $3 \mathrm{~h}$ in a round-bottom flask. The mixture was filtrated (in a $28 \mu \mathrm{m}$ mesh) to separate the black liquor from the acetosolv pulp (AP). The AP was washed with acetic acid (99.7\%) until the washing liquid was colorless, dried $\left(60^{\circ} \mathrm{C}, 24 \mathrm{~h}\right)$, and bleached with a solution of $5 \mathrm{wt} \% \mathrm{H}_{2} \mathrm{O}_{2}$ and $4 \%(\mathrm{w} / \mathrm{v}) \mathrm{NaOH}$ at $70^{\circ} \mathrm{C}$, at a $1: 10(\mathrm{w} / \mathrm{v}) \mathrm{AP}$ : solution ratio, for $3 \mathrm{~h}$. The material was then vacuum-filtered, washed with distilled water until its $\mathrm{pH}$ was equal to that of the washing water, ovendried at $60{ }^{\circ} \mathrm{C}$ for $24 \mathrm{~h}$, and the bleaching procedure was repeated, producing the bleached acetosolv pulp (BAP).

The cellulose nanocrystals (CNCs) were finally extracted from the BAP by an acid hydrolysis, as described by Nascimento et al. (2014) with modifications. The BAP was stirred in a $\mathrm{H}_{2} \mathrm{SO}_{4}$ solution (50 wt\%) at $45^{\circ} \mathrm{C}$ for $60 \mathrm{~min}$, at a $1: 20$ ratio (w/v, BAP: solution). The reaction was halted by adding 10 times the volume of cold $\left(10^{\circ} \mathrm{C}\right)$ deionized water. The suspension was submitted to three cycles of centrifugation at $2520 \mathrm{~g}$ for $30 \mathrm{~min}$ in a Beckman JS-4.2 centrifuge (Beckman Coulter, Brea, USA). After each centrifugation, the suspension was sonicated for $4 \mathrm{~min}$ in a probe Branson sonicator (Digital Sonifier 250, Branson Ultrasonics, Danbury, USA) at $20 \mathrm{kHz}$ in order to prevent CNC aggregation. After the third centrifugation, the supernatant was a bit turbid (instead of the previous supernatants, which were clear), indicating that the CNCs were beginning to migrate to the supernatant. The suspension was then dialyzed with distilled water until it reached a pH of 6-7 (approximately $48 \mathrm{~h}$, with four changes of water). The solid content of the dialysed CNC suspension was determined by gravimetry after drying at $105^{\circ} \mathrm{C}$ until constant weight in a drying oven (Memmert, Schwabach, Germany).

\subsection{Characterization of cellulose nanocrystals}

For the transmission electron microscopy (TEM) images, previously sonicated CNC suspensions were placed onto Formvar/carbon coated grids and negatively stained with $2 \%$ uranyl acetate. The samples were imaged using a Tecnai 20 Transmission Electron Microscope (FEI, Hillsboro, USA), with an acceleration voltage 
Table 1

$\alpha$-cellulose, hemicellulose, and lignin contents (on a dry weight basis) of the wheat straw and the isolated WSH (values represented as mean \pm standard deviation).

\begin{tabular}{lll}
\hline Fractions & Milled wheat straw & Hemicellulose powder \\
\hline$\alpha$-cellulose (\%) & $40.56 \pm 2.02$ & $3.55 \pm 0.14$ \\
Hemicelluloses (\%) & $32.95 \pm 1.77$ & $91.28 \pm 1.21$ \\
Lignin (\%) & $25.58 \pm 1.69$ & $4.47 \pm 0.21$ \\
\hline
\end{tabular}

of $200 \mathrm{kV}$, and a magnification of $14,500 \times$. The CNC dimensions (length and diameter) were taken as averages of 100 measurements taken by using the scale bar embedded in the image.

The zeta potential of CNCs was measured in triplicate using a Zetasizer Nano ZS 3000 (Malvern Instruments Ltd., Worcestershire, UK) for CNC suspensions diluted to $0.1 \mathrm{wt} \%$ with deionized water.

\subsection{Film formation}

The films were prepared according to a central composite design (Table 2 ) with two variables, i.e. CNC contents ( $0-8 \mathrm{wt} \%$ on WSH) and citric acid concentration (0-30 wt\% on WSH), the films being hereinafter referred to as CNC-X-CA-Y, $\mathrm{X}$ and $\mathrm{Y}$ being the $\mathrm{CNC}$ and citric acid contents (in wt\%), respectively, on a dry hemicellulose basis. A control film (without CNC or citric acid) was also produced. For each film, $3 \mathrm{~g}$ of WSH were mixed to $0.9 \mathrm{~g}$ glycerol, citric acid, CNC suspension, and distilled water. Citric acid and $\mathrm{CNC}$ suspensions were added according to the design and to the CNC content in the suspension. The volume of distilled water was determined so that the sum of volumes of CNC suspension and water was $60 \mathrm{~mL}$. The film forming mixtures were homogenized using an Ystral X10/25 (Ballrechtar-Dottingen, Germany) for $15 \mathrm{~min}$, degassed under vacuum, and treated in an ultrasonic bath at $50{ }^{\circ} \mathrm{C}$ for $2 \mathrm{~min}$. The films were cast on petri dishes to a final dried thickness of $0.09 \mathrm{~mm}$ and left to dry at $30^{\circ} \mathrm{C}$ for $24 \mathrm{~h}$ in a fan oven (Memmert, Schwabach, Germany). The dried films were cured at $140^{\circ} \mathrm{C}$ for $8 \mathrm{~min}$ in a fan oven, then conditioned ( $50 \% \mathrm{RH}, 24^{\circ} \mathrm{C}, 48 \mathrm{~h}$ ) in an environmental chamber (Weiss Gallenkamp, Loughborough, UK) previously to the determinations.

\subsection{Film characterization}

\subsubsection{Tensile tests}

Tensile tests were carried out on $50 \mathrm{~mm} \times 8 \mathrm{~mm}$ specimens according to D882-12 method (ASTM, 2012) on a Texture Analyzer TA.XT Plus (Stable Micro Systems, Godalming, UK) equipped with A/TG Tensile Grips and a $5 \mathrm{~kg}$ load cell. The thicknesses of the specimens were determined by using a micrometer screw gauge (Moore \& Wright, Sheffield, UK) to the nearest $0.01 \mathrm{~mm}$ at 5 random locations. The initial grip separation and crosshead speed were set to $40 \mathrm{~mm}$ and $1 \mathrm{~mm} / \mathrm{s}$, respectively. The reported values correspond to 5-6 measurements.

\subsubsection{Water vapor permeability (WVP)}

The water vapor permeability (WVP) determination was modified from E96-05 method (ASTM, 2016) for six samples, whose thicknesses were measured using a micrometer screw gauge (Moore \& Wright, Sheffield, UK) to the nearest $0.01 \mathrm{~mm}$ at 5 random locations. The test films were sealed as patches onto acrylic permeation cells ( $24 \mathrm{~mm}$ in diameter and $10 \mathrm{~mm}$ in height) containing $2 \mathrm{~mL}$ distilled water. The cells were placed in a desiccator connected to two channels providing a steady flow of dried air (less than $1 \%$ $\mathrm{RH}$ ) from a Balston $75-60$ air drier at $24^{\circ} \mathrm{C}$, and were weighed at least 7 times over a 24-h period.

\subsubsection{Insoluble matter}

The insoluble matter determination, conducted on $2 \mathrm{~cm} \times 2 \mathrm{~cm}$ film pieces (with 8 replicates), was based on the method proposed by Ojagh, Rezaei, Razavi, \& Hosseini, 2010, with some modifications. The films (presenting initial moisture contents of 7.0-7.5\%) were previously dried at $103^{\circ} \mathrm{C}$ for $24 \mathrm{~h}$. The dried samples were immersed in $50 \mathrm{~mL}$ of distilled water for $6 \mathrm{~h}$ at $25^{\circ} \mathrm{C}$ under stirring $(150 \mathrm{rpm})$. The dry weight of the remaining film pieces was obtained after filtration on previously dried filter paper, and it was used to calculate the insoluble matter as a percentage of the initial dry weight. All the dry weights (of initial and final film pieces and the filter papers) were determined after drying at $103^{\circ} \mathrm{C}$ for $24 \mathrm{~h}$ using a fan oven (Memmert, Schwabach, Germany).

\subsubsection{Opacity}

Film opacity was determined (in quadruplicate) as described by Irissin-Mangata, Bauduin, Boutevin, \& Gontard, 2001. $1 \mathrm{~cm} \times 5 \mathrm{~cm}$ film strips were placed on the internal side of a Varian Cary 50 UV-vis spectrophotometer cell (Agilent Technologies, Santa Clara, CA, USA), perpendicularly to the light beam. The absorbance spectrum $(400-800 \mathrm{~nm})$ of film samples was recorded, and opacity was defined as the area under the recorded curve (estimated by the linear trapezoidal rule) and expressed as absorbance units $\times$ nanometers (wavelength) per millimeter (film thickness) $\left(A \mathrm{~nm} \mu \mathrm{m}^{-1}\right)$.

\subsubsection{Fourier transform infrared (FTIR)}

The FTIR spectra (128 scans at $2 \mathrm{~cm}^{-1}$ resolution for a spectral range from 4000 to $800 \mathrm{~cm}^{-1}$ ) were recorded using a Nicolet Magna-IR 860 FTIR spectrometer (Thermo Nicolet, Madison, WI, USA). Samples were placed on a GoldenGate diamond ATR accessory (Specac, Orpington, Kent). The empty crystal was used as reference.

\subsubsection{Scanning electron microscopy (SEM)}

The scanning electron microscopy (SEM) images of gold-coated film surfaces were taken using a Zeiss Supra 55 VP SEM (Zeiss, Oberkochen, Germany) with an acceleration voltage of $3 \mathrm{kV}$, and a magnification of $2000 \times$.

\subsubsection{Statistical analyses and optimization}

The software Minitab ${ }^{\circledR} 15$ (Minitab Inc, State College, PA, USA) was used for regression analyses and assessment of regression coefficients for tensile tests, water vapor permeability, insoluble matter, and opacity. The models were checked for adequacy based on ANOVA and the F-test at 95\% confidence level, and also for coefficients of determination $\left(\mathrm{R}^{2}\right)$. Moreover, they were used for drawing contour plots.

The optimized conditions were defined by using the Response Optimizer function $\left(\right.$ Minitab $^{\circledR}$ ) as those resulting in maximum water resistance (target insoluble matter: $50 \mathrm{~g} / 100 \mathrm{~g}$ ) and minimum WVP (target: $1.5 \mathrm{gmm} \mathrm{h}^{-1} \mathrm{kPa}^{-1} \mathrm{~m}^{-2}$ ), in order to obtain films with a relatively low water sensibility to be used for food wrapping and coating applications. At the same time, the tensile properties were balanced by combining the following requisites on tensile properties: (a) maximum tensile strength (lower: $4 \%$, the lower acceptable value for food packaging materials, according to Tajeddin, Rahman, \& Abdulah, 2010; target: $8 \mathrm{MPa}$ ); (b) maximum modulus (target: $400 \mathrm{MPa}$, which is comparable to polyethylene, according to Ku, Wang, Pattarachaiyakoop, \& Trada, 2011); and a reasonable elongation (no lower than $2 \%$, which is comparable to that of polystyrene, according to Ku et al., 2011; target: 5\%). The conditions set as optimum were then experimentally verified (in three repetitions, each with determinations in triplicate), and 
Table 2

Experimental conditions for each run (in gray) and responses for film properties.

\begin{tabular}{|c|c|c|c|c|c|c|c|c|c|c|}
\hline \multirow[t]{2}{*}{ Run } & \multicolumn{2}{|c|}{ CNC (wt\%) } & \multicolumn{2}{|c|}{$\mathrm{CA}(\mathrm{wt} \%)$} & \multirow[t]{2}{*}{$\sigma$} & \multirow[t]{2}{*}{$\varepsilon$} & \multirow[t]{2}{*}{ E } & \multirow[t]{2}{*}{ WVP } & \multirow[t]{2}{*}{ IM } & \multirow[t]{2}{*}{ OP } \\
\hline & $\mathrm{U}$ & C & $\mathrm{U}$ & C & & & & & & \\
\hline Control & 0 & -1.41 & 0 & -1.41 & 9.87 & 3.25 & 555.7 & 4.609 & 4.51 & 9.23 \\
\hline 1 & 1.2 & -1 & 4.36 & -1 & 12.92 & 3.35 & 870.9 & 2.900 & 12.19 & 9.95 \\
\hline 2 & 6.8 & 1 & 4.36 & -1 & 15.47 & 3.13 & 1250.2 & 1.966 & 21.77 & 14.60 \\
\hline 3 & 1.2 & -1 & 25.64 & 1 & 8.94 & 3.32 & 535.4 & 2.569 & 32.84 & 10.23 \\
\hline 4 & 6.8 & 1 & 25.64 & 1 & 11.77 & 2.87 & 804.3 & 1.663 & 49.47 & 14.14 \\
\hline 5 & 0 & -1.41 & 15 & 0 & 8.71 & 3.75 & 443.1 & 3.447 & 15.18 & 9.09 \\
\hline 6 & 8 & 1.41 & 15 & 0 & 14.98 & 2.36 & 1001.0 & 1.970 & 28.60 & 19.31 \\
\hline 7 & 4 & 0 & 0 & -1.41 & 11.25 & 3.13 & 864.6 & 3.013 & 6.52 & 12.77 \\
\hline 8 & 4 & 0 & 30 & 1.41 & 8.28 & 5.40 & 558.4 & 1.680 & 42.57 & 12.30 \\
\hline 9 & 4 & 0 & 15 & 0 & 11.51 & 3.43 & 837.0 & 2.487 & 27.71 & 15.89 \\
\hline 10 & 4 & 0 & 15 & 0 & 11.50 & 3.86 & 777.1 & 2.484 & 27.53 & 17.30 \\
\hline 11 & 4 & 0 & 15 & 0 & 10.10 & 3.33 & 788.6 & 2.105 & 24.99 & 15.17 \\
\hline
\end{tabular}

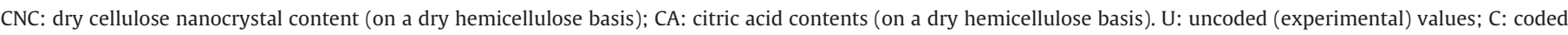

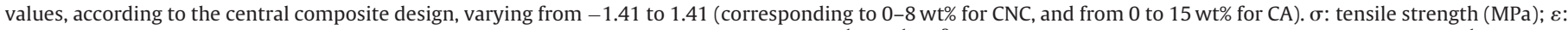
elongation at break (\%); E: elastic modulus (MPa); WVP: water vapor permeability $\left(\mathrm{g} \mathrm{mm} \mathrm{h}^{-1} \mathrm{kPa}^{-1} \mathrm{~m}^{-2}\right)$; IM: insoluble matter ( $\left.\mathrm{g} / 100 \mathrm{~g}\right)$; OP: opacity (A nm $\mu \mathrm{m}^{-1}$ ).

the mean relative deviation modulus $(G)$ was calculated for each response.

\section{Results and discussion}

\subsection{Yield and characterization of WSH}

The WSH extraction resulted in a yield of $16.7 \mathrm{wt} \%$ on a dry wheat straw basis. This yield was lower than the one reported in our previous study (Azeredo et al., 2015), probably because a higher $\mathrm{H}_{2} \mathrm{O}_{2}$ concentration was used, removing more lignins. This is supported by the higher hemicellulose content of WSH (Table 1) when compared to the one of the previous study ( $87 \mathrm{wt} \%$ as reported by Azeredo et al., 2015), indicating that less impurities were present to the hemicelluloses. The neutral sugar composition, as determined from GC-FID, was: xylose, 79.26\%; arabinose, 7.68\%; rhamnose, $5.03 \%$; glucose, $2.85 \%$; galactose, $2.75 \%$; mannose, $2.42 \%$. This result confirms arabinoxylans as the predominant hemicelluloses in wheat straw, with an arabinose/xylose (Ara/Xyl) ratio of about $1: 10$, similar to values reported in previous studies (Faryar et al., 2015; Merali et al. 2013).

\subsection{Characterization of the CNC suspension}

Each $100 \mathrm{~g}$ of dried wheat straw resulted in the production of $12.4 \mathrm{~g}$ of CNC (on a dry basis). Considering the $\alpha$-cellulose of 40.56 wt\% (Table 1), the CNC isolation yield is thus estimated to be about $30 \%$ with respect to the $\alpha$-cellulose content, which is similar or higher than yields of CNC reported in other studies (Bondeson, Mathew, \& Oksman, 2006; Filson, Dawson-Andoh, \& SchweglerBerry, 2009).

Fig. 1 shows TEM micrographs of CNCs isolated from wheat straw. The nanocrystals were presented as well dispersed needlelike structures, with lengths ranging from $84 \mathrm{~nm}$ to $306 \mathrm{~nm}$ (average $180 \mathrm{~nm}$ ) and diameters ranging from $4 \mathrm{~nm}$ to $18 \mathrm{~nm}$ (average $9 \mathrm{~nm}$ ), resulting in an average aspect ratio (L/W) of 20.

The zeta potential of the CNCs was measured as $-25.9 \mathrm{mV}$, slightly higher (in absolute value) than $25 \mathrm{mV}$, the minimum value considered for a dispersion to be considered stable, i.e., for the repulsive forces to be strong enough to overcome the Van der Waals attraction forces; the CNCs are thus not expected to aggregate (Moon et al., 2005). Since the $\mathrm{CNCs}$ were obtained by $\mathrm{H}_{2} \mathrm{SO}_{4}$ hydrolysis, their zeta potential indicates the degree of repulsion between nanocrystals induced by sulfate groups (Lin \& Dufresne, 2014).

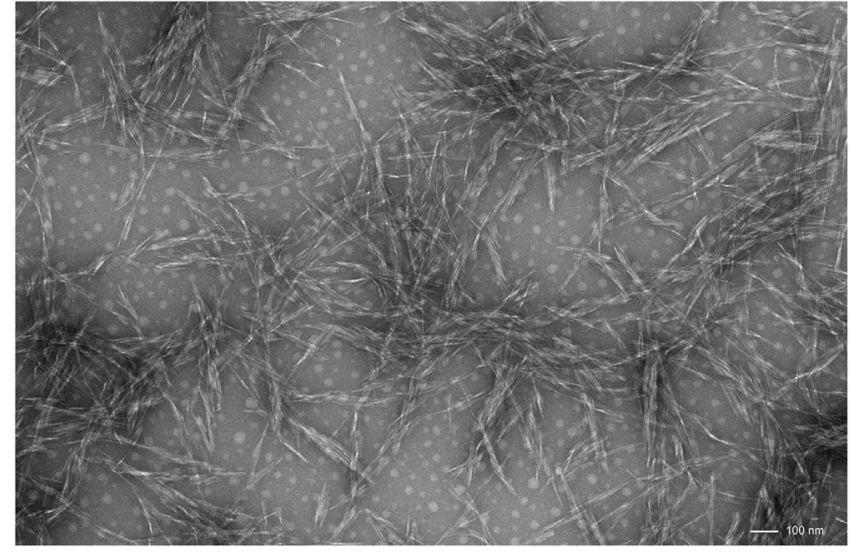

Fig. 1. Transmission electron micrograph of celulose nanocrystals from wheat straw (magnification $14,500 \times$ ).

\subsection{Characterization of films}

The properties of the films obtained from each treatment are presented in Table 2, while Table 3 presents the regression models for each property. All regressions were significant $(p<0.05)$ except the one for elongation; the lack of fit was non-significant for all models, and the $\mathrm{R}^{2}$ values were above $80 \%$ (except the one for elongation). Fig. 2 presents the contour plots for the experimental responses, which are graphical representations of the models.

\subsubsection{Insoluble matter and water vapor permeability (WVP)}

The CNCs increased insoluble matter (Table 3, Fig. 2), since CNCs are insoluble in water (George \& Sabapathi, 2015). The water insolubility and high cristallinity of CNCs make them basically impermeable to water molecules, which creates a tortuous path for water vapor to pass through the film, making the permeant molecules to travel a longer distance, which explains the reduced WVP by CNC addition (El Miri et al., 2015). Hydrogen bonds between the hemicellulose matrix and CNC, as suggested by Rhim \& Ng (2007), might also contribute to improve water resistance. Citric acid also significantly increased the insoluble matter of the films and decreased WVP, which seems to be in accordance with previous studies which present citric acid as crosslinking agent to polysaccharide films (Olivato, Grossmann, Bilck, \& Yamashita, 2012; Reddy \& Yang, 2010; Reddyet al., 2012). 
Table 3

Regression coefficients (for the coded values) and statistical parameters of the models.

\begin{tabular}{|c|c|c|c|c|c|c|}
\hline Terms & $\sigma$ & $\varepsilon$ & $E$ & WVP & IM & $\mathrm{OP}$ \\
\hline Mean & 11.04 & 3.54 & 800.88 & 2.36 & 26.74 & 16.12 \\
\hline $\mathrm{X}_{1}$ & 1.78 & -0.33 & 179.66 & -0.49 & 5.65 & 2.88 \\
\hline$X_{2}$ & -1.48 & 0.36 & -151.81 & -0.32 & 12.41 & -0.11 \\
\hline $\mathrm{X}_{1}^{2}$ & 0.77 & -0.36 & -2.31 & 0.11 & -0.96 & -1.24 \\
\hline $\mathrm{X}_{2}{ }^{2}$ & -0.27 & 0.24 & -7.56 & 0.07 & 0.36 & -2.08 \\
\hline $\mathrm{X}_{1}{ }^{*} \mathrm{X}_{2}$ & 0.07 & -0.06 & -27.59 & 0.01 & 1.76 & -0.18 \\
\hline$F_{\text {reg }}$ & 5.52 & 1.44 & 7.00 & 6.68 & 18.75 & 10.05 \\
\hline $\mathrm{p}$ & 0.04 & 0.35 & 0.03 & 0.03 & $<0.01$ & 0.01 \\
\hline $\mathrm{F}_{\text {lof }}$ & 3.73 & 9.12 & 20.38 & 2.29 & 10.92 & 1.97 \\
\hline $\mathrm{p}$ & 0.21 & 0.10 & 0.05 & 0.32 & 0.08 & 0.35 \\
\hline $\mathrm{R}^{2}(\%)$ & 84.67 & 58.99 & 87.49 & 86.97 & 94.94 & 90.95 \\
\hline
\end{tabular}

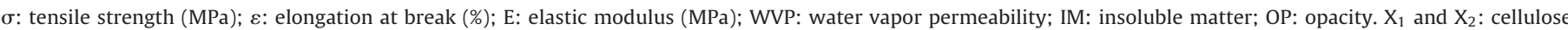

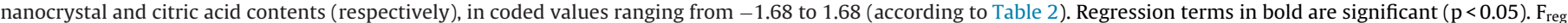
and $\mathrm{F}_{\text {lof }}$ : $\mathrm{F}$ values for regression and lack-of-fit, respectively, with the corresponding $\mathrm{p}$ values below; $\mathrm{R}^{2}$ : coefficients of determination.
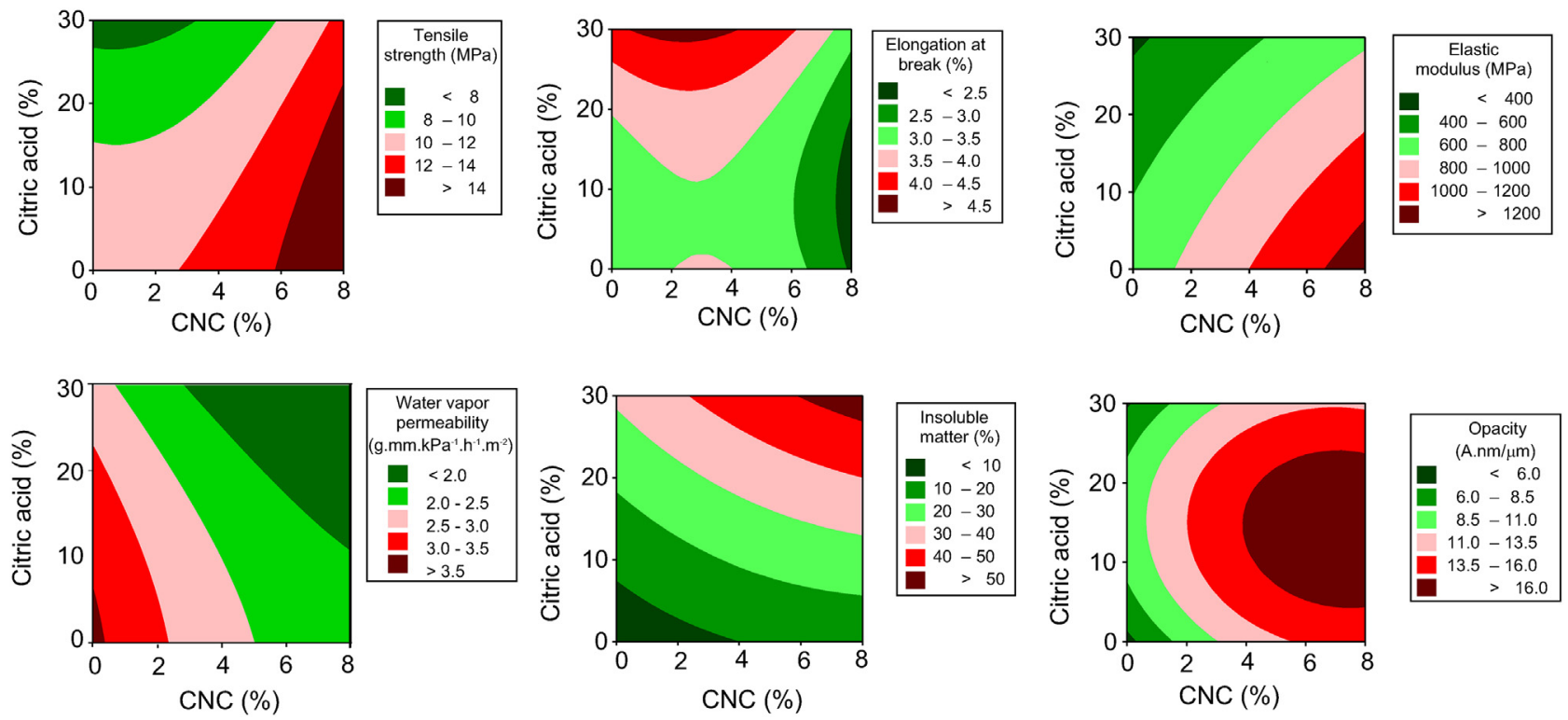

Fig. 2. Graphical representation of the regression models for tensile properties, water vapor permeability, insoluble matter, and opacity of the films.

\subsubsection{Tensile properties}

When compared to a film from corn hull arabinoxylans with a similar glycerol content (Zhang \& Whistler, 2004), the control WSH hemicellulose film (Table 2) presented a similar tensile strength, higher modulus, and lower elongation. When compared to the WSH films obtained in our previous study (Azeredo et al., 2015), the control WSH film also presented similar strength but lower elongation and, most noticeably, much higher modulus, which may be explained by the higher hemicellulose content (which probably means that the remaining lignin content was lower). Citric acid impaired both strength and modulus, suggesting a plasticizing effect by citric acid, which has been reported in other studies (Abdillahi, Chabrat, Rouilly, \& Rigal, 2013; Chabrat et al., 2012). Although it seems contradictory that the same compound may present coexisting plasticizing and crosslinking effects, some studies have reported a similar behaviour for citric acid in polysaccharide films (Sebti, Delves-Broughton, \& Coma, 2003; Shi et al., 2008; Wang, Ren, Li, Sun, \& Liu, 2014), including our previous study on WSH films (Azeredo et al., 2015). A possible explanation is that glycerol may act as a crosslinking extender to citric acid (Jiang, Reddy, Zhang, Roscioli, \& Yang, 2013; Yao, Wang, Ye, \& Yang, 2013), which may provide flexibility to the crosslinking (Yao et al., 2013). Although chemical crosslinking usually restrict the mobility of polymer chains, a flexible crosslinking agent may act similarly to a plasticizer (Hu, Song, Liu, \& Zhang, 2010; Jia, Zhang,
He, \& Ning, 2005; Zhang, Hu, Jia, \& Du, 2003). The flexibility of a glycerol-extended citric acid crosslinking might thus explain why the crosslinking reduced the film solubility while impairing tensile strength and modulus.

On the other hand, the negative effects of citric acid on both tensile strength and elastic modulus were compensated for by the positive effects of CNCs on those properties (Table 3, Fig. 2). The increasing strength resulting from CNC addition is explained by surface interactions between CNCs and the matrix as well as to the reinforcing effect through stress transfer at the CNC-matrix interface, while the increasing modulus is ascribed to a higher stiffness of the films by CNC addition (Khan et al., 2012). According to Eq. (1) (Favier, Dendievel, Canova, Cavaille, \& Gilormini, 1997), the theoretical percolation threshold $\left(\& \mathrm{x} 3 \mathrm{D} 5\right.$; $\left._{\mathrm{v}}\right)$ for the cellulose nanocrystals isolated from wheat straw with an average aspect ratio (L/W) of 20 would be $3.5 \mathrm{vol} \%$.

$\varphi_{v}=\frac{0.7}{L / W}$

Considering the densities of CNC, WSH, glycerol, and citric acid as $1.6 \mathrm{gcm}^{-3}$ (Dufresne, 2013), $1.2 \mathrm{gcm}^{-3}$ (as measured by hydrostatic weighing), $1.26 \mathrm{gcm}^{-3}$, and $1.66 \mathrm{gcm}^{-3}$, respectively, the $\mathrm{CNC}$ theoretical weight fraction required to form a percolated network in glycerol-plasticized WSH films containing $15 \mathrm{wt} \%$ citric acid (the average value used in this study) would be about 
Table 4

Predicted and experimental responses obtained from the optimized conditions (5.9 wt\% CNC and $30 \mathrm{wt} \%$ citric acid).

\begin{tabular}{llll}
\hline Response & Predicted & Experimental & $\boldsymbol{G}$ \\
\hline$\sigma(\mathrm{MPa})$ & 10.01 & $9.76 \pm 0.56$ & 6.06 \\
$\varepsilon(\%)$ & 4.09 & $3.94 \pm 0.32$ & 9.62 \\
$\mathrm{E}(\mathrm{MPa})$ & 664.5 & $656.3 \pm 40.0$ & 6.25 \\
$\mathrm{WVP}\left(\mathrm{g} \mathrm{mm} \mathrm{h}{ }^{-1} \mathrm{kPa}^{-1} \mathrm{~m}^{-2}\right)$ & 1.502 & $1.516 \pm 0.120$ & 7.83 \\
$\mathrm{IM}(\mathrm{g} / 100 \mathrm{~g})$ & 50.06 & $52.59 \pm 3.68$ & 8.12 \\
$\mathrm{OP}\left(\mathrm{A} . \mathrm{nm} . \mu \mathrm{m}^{-1}\right)$ & 13.02 & $14.31 \pm 1.11$ & 10.17
\end{tabular}

$\sigma$ : tensile strength; $\varepsilon$ : elongation at break; E: elastic modulus; WVP: water vapor permeability; IM: insoluble matter; OP: opacity. $G$ : mean relative deviation modulus.

4.4 wt\%. At CNC contents above this percolation threshold, CNCs are expected to form a continuous hydrogen bond-linked network, effectively improving the tensile properties of films (Favier et al., 1997). Indeed, according to the regressions, a film with $15 \mathrm{wt} \%$ citric acid and $4.4 \mathrm{wt} \% \mathrm{CNC}$ would present a predicted tensile strength of 11.3 MPa and an elastic modulus of $826 \mathrm{MPa}$, representing increases of about $14 \%$ and $48 \%$ (respectively) when in comparison with the control film.

\subsubsection{Opacity}

The film opacity was increased by CNC concentration (Table 3, Fig. 2), which is probably due to difference between the refractive index of CNC and the matrix (Bardet, Belgacem, \& Bras, 2013), although some CNC aggregation within the matrix may have contributed to this effect (Pereda, Dufresne, Aranguren, \& Marcovich, 2014). Citric acid did not affect significantly the opacity of the films $(\mathrm{p}>0.05)$.

\subsubsection{Optimization}

The optimized conditions, as defined previously, were: $5.9 \mathrm{wt} \%$ CNC and $30 \mathrm{wt} \%$ citric acid, which (with a composite desirability 1 $(D)$ of 0.93 ). The predicted properties at those conditions, as well as the corresponding experimental values and mean relative deviation modulus $(G)$ are presented at Table 4 . The $G$ values of most models were between 5 and 10 , indicating reasonably good predictions, except the one for opacity, whose prediction was rather poor $(G>10)$ (Roy, Gennadios, Weller, \& Testin, 2000).

When compared to conventional polymers, the tensile strength of the optimized film was comparable to that of low-density polyethylene (LDPE) (Arrakhiz et al., 2013; De Vlieger, 2003; Salmah, Romisuhani, \& Akmal, 2011), and its modulus was within the range for high-density polyethylene (HDPE) (Ku et al., 2011), while the elongation was still almost as low as that of polystyrene (PS) (Ku et al., 2011). When compared to the control WSH film, there were increases in modulus (by 18\%), elongation (by $21 \%$ ), insoluble matter (by 11 -fold), and opacity (by 55\%), while WVP decreased by $67 \%$.

\subsubsection{Fourier transform infrared spectroscopy (FTIR)}

Fig. 3 shows the Fourier transform infrared (FTIR) spectra of the hemicelluloses and films. Some bands are related to the structure of the hemicelluloses, namely, antisymmetric $\mathrm{C}-\mathrm{O}-\mathrm{C}$ stretching of glycosidic links at $1158 \mathrm{~cm}^{-1}$ (Robert, Marquis, Barron, Guillon, \& Saulnier, 2005), C-O stretch at $1040 \mathrm{~cm}^{-1}$ (Mohebby, 2008; Peng et al., 2012a), C-H and $\mathrm{O}-\mathrm{H}$ bending at $1408 \mathrm{~cm}^{-1}$ and $1326 \mathrm{~cm}^{-1}$, respectively (Peng et al., 2012a), and C-1 frequency

\footnotetext{
1 For an optimization, upper and/or lower limits are set for each response, as well as target values. A desirability value may vary from 0 (when the response value is beyond the acceptable limits) to 1 (when the target is reached). The desirability values of all responses are then combined into the composite desirability $(D)$, which is to be maximized.
}

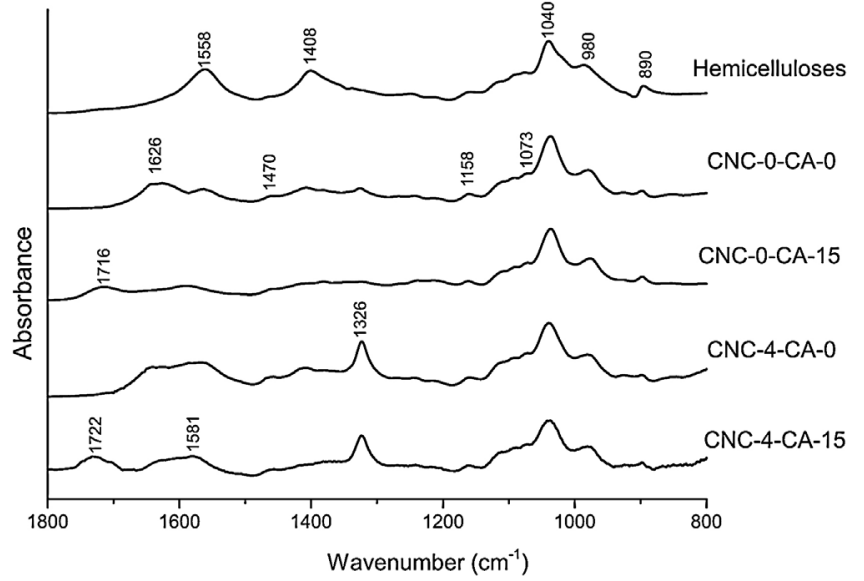

Fig. 3. FTIR of wheat straw hemicelluloses and films. Films identified as CNC-X-CA$\mathrm{Y}$ contain $\mathrm{X}$ wt\% cellulose nanocrystals and Y wt\% citric acid on a dry hemicellulose basis.

(ring frequency) at $890 \mathrm{~cm}^{-1}$, characteristic of $\beta$-glycosidic linkages between xylose units (Peng et al., 2012a; Robert, Marquis, Barron, Guillon, \& Saulnier, 2005). The relative intensities of the major band at $1040 \mathrm{~cm}^{-1}$ and the shoulder at $1073 \mathrm{~cm}^{-1}$ are related to the level of arabinose substitution in arabinoxylans (Toole et al., 2012), and the band at $980 \mathrm{~cm}^{-1}$ is also ascribed to the presence of arabinose side chains in arabinoxylans (Peng et al., 2012b; Robert et al., 2005). The bands at $1560-1580 \mathrm{~cm}^{-1}$ and $1470 \mathrm{~cm}^{-1}$ are ascribed to remaining lignin (Lupoi, Singh, Parthasarathi, Simmons, \& Henry, 2015). The band at $1626 \mathrm{~cm}^{-1}$ (absorbed water in the films) decreased in intensity when citric acid was present, probably because some of the hydrophilic groups were involved in the crosslinking, thus the films absorbed less water. The occurrence of crosslinking is indicated by the presence of small bands around $1710--1720 \mathrm{~cm}^{-1}$ in films with citric acid (Coma et al., 2003), which correspond to ester $\mathrm{C}=\mathrm{O}$ stretching vibration (Dastidar \& Netravali, 2012; Shi et al., 2007; Wang et al., 2014).

\subsubsection{Scanning electron microscopy (SEM)}

The SEM images (Fig. 4) show that the presence of citric acid promotes the formation of sandy surfaces when compared to the relatively smooth surface of the control (CNC-0-CA-0) film, which is in agreement with the observations by Bonilla et al. [2013]. The concomitant presence of cellulose nanocrystals makes the films even rougher (corroborating Khan et al., 2012, and Qi, Cai, Zhang, \& Kuga, 2009), with filamentous structures uniformly dispersed within the matrix, which contributed to the effectiveness of CNCs in improving the tensile properties of the films (Fig. 2). All films presented a relatively uniform dispersion of their components, without remarkable discontinuities, cracks or aggregates.

\section{Conclusions}

Films have been successfully formed from wheat straw hemicelluloses added with different contents of wheat straw cellulose nanocrystals (with an average aspect ratio of 20) and citric acid. The water resistance and barrier to water vapor of the films were enhanced by both cellulose nanocrystals (CNCs) and citric acid. Although the role of citric acid as a crosslinker has been evidenced by FTIR as well as by increased water resistance of films, the addition of citric acid also resulted in decreased tensile strength and modulus of films, suggesting a concomitant plasticizing effect, which was attributed to a crosslinking extension by glycerol, providing flexibility to the crosslinking. On the other hand, those negative effects of citric acid were compensated for by CNCs, which 


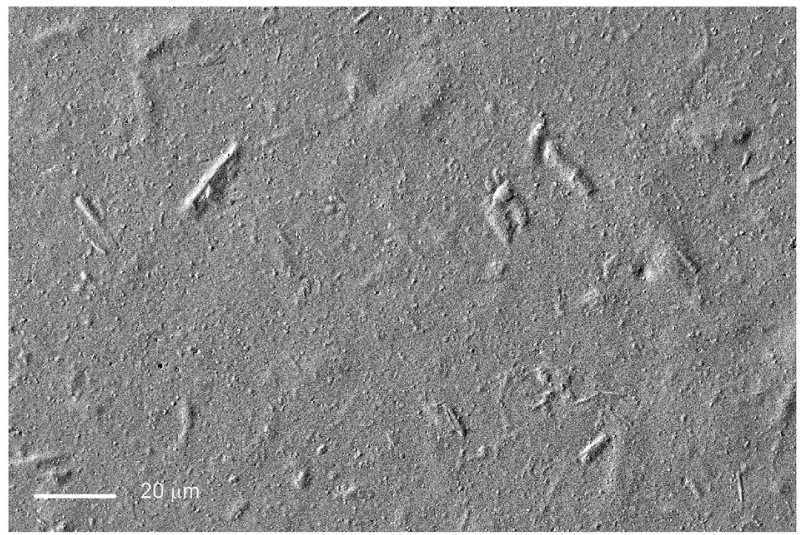

CNC-0-CA-0

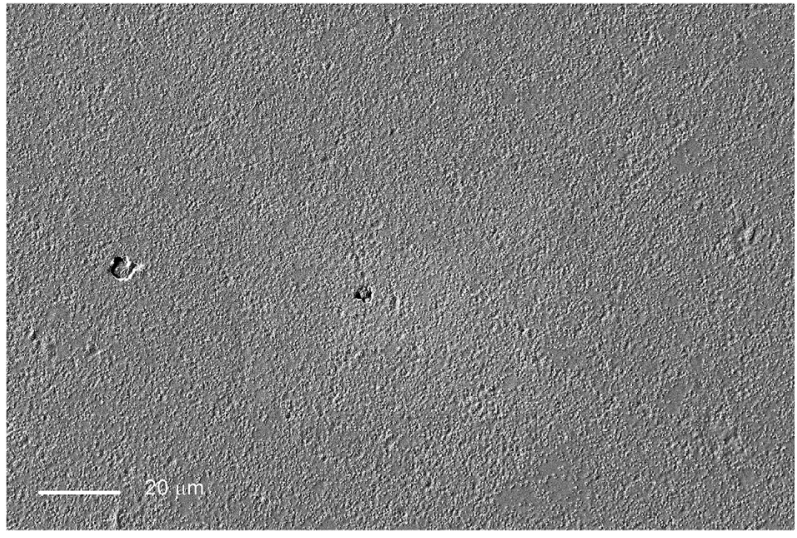

CNC-0-CA-15

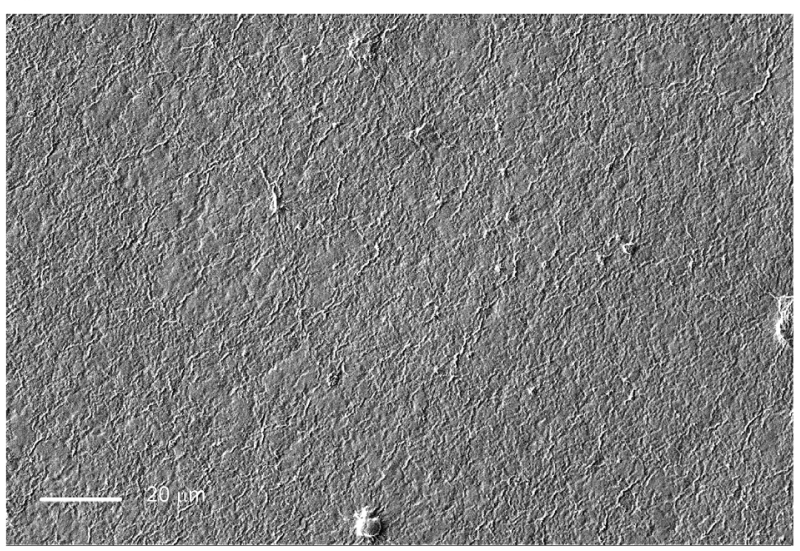

CNC-4-CA-15

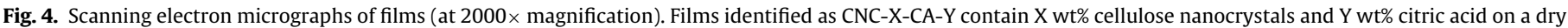
hemicellulose basis.

improved those properties. The combination of a reinforcing agent (CNC) and a crosslinker (citric acid) was demonstrated to produce films with a good combination of physical properties for potential use as biodegradable wrapping or coating to a variety of foods. The optimized conditions (defined as those resulting in minimum water solubility and permeability and a good combination of tensile properties) were defined as $5.9 \mathrm{wt} \% \mathrm{CNC}$ and $30 \mathrm{wt} \%$ citric acid. The elastic modulus, elongation, water vapor barrier, and water resistance were enhanced when compared to the control films, while there was some loss of transparency.

\section{Acknowledgements}

The authors gratefully acknowledge the Labex Program by Brazilian Agricultural Research Corporation (Embrapa), United Kingdom Biotechnology and Biological Sciences Research Council (BBSRC) Institute Strategic Programme 'Food and Health' (grant number BB/J004545/1), and BBSRC/EMBRAPA collaboration project (grant number BBS/E/F/00042712). Authors also thank the National Counsel of Technological and Scientific Development (CNPq, Brazil) for the Research Productivity Fellowships granted to M.F. Rosa and E.S. Brito (processes 310368/2012-0 and 302770/2015-1, respectively) and for the scholarship granted to P.H.F. Pereira (243244/2013-4).

\section{References}

ASTM D882-12. (2012). Standard test method for tensile properties of thin plastic sheeting. West Conshohocken: ASTM International.

ASTM E96/E96M-16. (2016). Standard test methods for water vapor transmission of materials. West Conshohocken: ASTM International.
Abdillahi, H., Chabrat, E., Rouilly, A., \& Rigal, L. (2013). Influence of citric acid on thermoplastic wheat flour/poly(lactic acid) blends: II. Barrier properties and water vapor sorption isotherms. Industrial Crops and Products, 50, 104-111.

Abdul Khalil, H. P. S., Bhat, A. H., \& Yusra, A. F. I. (2012). Green composites from sustainable cellulose nanofibrils: a review. Carbohydrate Polymers, 87, 963-979.

Arrakhiz, F. Z., El Achaby, M., Malha, M., Bensalah, M. O., Fassi-Fehri, O., Bouhfid, R., et al. (2013). Mechanical and thermal properties of natural fibers reinforced polymer composites: doum/low density polyethylene. Materials E Design, 43, 200-205.

Azeredo, H. M. C., Kontou-Vrettou, C., Moates, G. K., Wellner, N., Cross, K., Pereira, P. H. F., et al. (2015). Wheat straw hemicellulose films as affected by citric acid. Food Hydrocolloids, 50, 1-6.

Balaguer, M. P., Gómez-Estaca, J., Gavara, R., \& Hernandez-Muñoz, P. (2011). Functional properties of bioplastics made from wheat gliadins modified with cinnamaldehyde. Journal of Agricultural and Food Chemistry, 59, 6689-6695.

Bondeson, D., Mathew, A., \& Oksman, K. (2006). Optimization of the isolation o nanocrystals from microcrystalline cellulose by acid hydrolysis. Cellulose, 13, 171-180.

Bonilla, J., Talón, E., Atarés, L., Vargas, M., \& Chiralt, A. (2013). Effect of the incorporation of antioxidants on physicochemical and antioxidant properties of wheat starch-chitosan films. Journal of Food Engineering, 118, 271-278.

Chabrat, E., Abdillahi, H., Rouilly, A., \& Rigal, L. (2012). Influence of citric acid on thermoplastic wheat flour/poly(lactic acid) blends. I: Thermal, mechanical and morphological properties. Industrial Crops and Products, 37, 238-246.

Cherubini, F. (2010). The biorefinery concept: using biomass instead of oil for producing energy and chemicals. Energy Conversion and Management, 51, $1412-1421$

Cho, M.-J., \& Park, B.-D. (2011). Tensile and thermal properties of nanocellulose-reinforced poly(vinyl alcohol) nanocomposites. Journal of Industrial and Engineering Chemistry, 17, 36-40.

Coma, V., Sebti, I., Pardon, P., Pichavant, F. H., \& Deschamps, A. (2003). Film properties from crosslinking of cellulosic derivatives with a polyfunctional carboxylic acid. Carbohydrate Polymers, 51, 265-271.

Dastidar, T. G., \& Netravali, A. N. (2012). 'Green' crosslinking of native starches with malonic acid and their properties. Carbohydrate Polymers, 90, 1620-1628.

De Vlieger, J. J. (2003). Green plastics for food packaging. In R. Ahvenainen (Ed.), Novel food packaging techniques (pp. 519-534). Boca Raton: CRC Press.

Dufresne, A. (2013). Nanocellulose: a new ageless bionanomaterial. Materials Today, 16, 220-227 
El Miri, N., Abdelouahdi, K., Barakat, A., Zahouily, M., Fihri, A., Solhy, A., et al. (2015). Bio-nanocomposite films reinforced with cellulose nanocrystals: rheology of film-forming solutions, transparency, water vapor barrier and tensile properties of films. Carbohydrate Polymers, 129, 156-167.

Fang, J. M., Sun, R. C., Salisbury, D., Fowler, P., \& Tomkinson, J. (1999). Comparative study of hemicelluloses from wheat straw by alkali and hydrogen peroxide extractions. Polymer Degradation and Stability, 66, 423-432.

Faryar, R., Linares-Pastén, J., Immerzeel, P., Mamo, G., Andersson, M., Stålbrand, H., et al. (2015). Production of prebiotic xylooligosaccharides from alkaline extracted wheat straw using the K80R-variant of a thermostable alkali-tolerant xylanase. Food and Bioproducts Processing, 93, 1-10

Favier, V., Canova, G. R., Cavaillé, J. Y., Chanzy, H., Dufresne, A., \& Gauthier, C. (1995). Nanocomposite materials from latex and cellulose whiskers. Polymers for Advanced Technologies, 6, 351-355.

Favier, V., Dendievel, R., Canova, G., Cavaille, J. Y., \& Gilormini, P. (1997). Simulation and modeling of three-dimensional percolating structures: Case of a latex matrix reinforced by a network of cellulose fibers. Acta Materialia, 45, $1557-1565$.

Filson, P. B., Dawson-Andoh, B. E., \& Schwegler-Berry, D. (2009). Enzymatic-mediated production of cellulose nanocrystals from recycled pulp. Green Chemistry, 11, 1808-1814.

George, J., \& Sabapathi, S. N. (2015). Cellulose nanocrystals: synthesis, functional properties, and applications. Nanotechnology, Science and Applications, 8, 45-54.

Hu, J.-S., Song, Z.-W., Liu, C., \& Zhang, W.-C. (2010). Influence of different nematic crosslinking unit on mesomorphism of side-chain cholesteric elastomers containing methyl groups. Colloid and Polymer Science, 288, 851-858.

Irissin-Mangata, J., Bauduin, G., Boutevin, B., \& Gontard, N. (2001). New plasticizers for wheat gluten films. European Polymer Journal, 37, 1533-1541.

Jacquemin, L., Mogni, A., Zeitoun, R., Guinot, C., Sablayrolles, C., Saulnier, L., et al. (2015). Performance evaluation of a semi-industrial production process of arabinoxylans from wheat bran. Process Biochemistry, 50, 605-613.

Jia, Y.-G., Zhang, B.-Y., He, X.-Z., \& Ning, J.-Z. (2005). Synthesis and phase behavior of nematic liquid-crystalline elastomers derived from smectic crosslinking agent. Journal of Applied Polymer Science, 98, 1712-1719.

Jiang, Q., Reddy, N., Zhang, S., Roscioli, N., \& Yang, Y. (2013). Water-stable electrospun collagen fibers from a non-toxic solvent and crosslinking system. Journal of Biomedical Materials Research Part A, 101A, 1237-1247.

Jonoobi, M., Oladi, R., Davoudpour, Y., Oksman, K., Dufresne, A., Hamzeh, Y., et al. (2015). Different preparation methods and properties of nanostructured cellulose from various natural resources and residues: A review. Cellulose, 22, 935-969.

Khan, A., Khan, R. A., Salmieri, S., Le Tien, C., Riedl, B., Bouchard, J., et al. (2012). Mechanical and barrier properties of nanocrystalline cellulose reinforced chitosan based nanocomposite films. Carbohydrate Polymers, 90, 1601-1608.

Ku, H., Wang, H., Pattarachaiyakoop, N., \& Trada, M. (2011). A review on the tensile properties of natural fiber reinforced polymer composites. Composites: Part $B$, 42, 856-873.

Lin, N., \& Dufresne, A. (2014). Surface chemistry, morphological analysis and properties of cellulose nanocrystals with gradiented sulfation degrees. Nanoscale, 6, 5384-5393.

Lupoi, J. S., Singh, S., Parthasarathi, R., Simmons, B. A., \& Henry, R. J. (2015). Recent innovations in analytical methods for the qualitative and quantitative assessment of lignin. Renewable and Sustainable Energy Reviews, 49, 871-906.

Mülhaupt, R. (2013). Green polymer chemistry and bio-based plastics: dreams and reality. Macromolecular Chemistry and Physics, 214, 159-174.

Merali, Z., Ho, J. D., Collins, S. R. A., Le Gall, G., Elliston, A., Käsper, A., et al. (2013). Characterization of cell wall components of wheat straw following hydrothermal pretreatment and fractionation. Bioresource Technology, 131, 226-234.

Mohebby, B. (2008). Application of ATR infrared spectroscopy in wood acetylation. Journal of Agricultural Science and Technology, 10, 253-259.

Montane, D., Farriol, X., Salvado, J., Jollez, P., \& Chornet, E. (1998). Application of steam explosion to the fractionation and rapid vapor-phase alcaline pulping of wheat straw. Biomass and Bioenergy, 14, 261

Moon, J. S., Park, J. H., Lee, T. Y., Kim, Y. W., Yoo, J. B., Park, C. Y., et al. (2005). Transparent conductive film based on carbon nanotubes and PEDOT composites. Diamond and Related Materials, 14, 1882-1887.

Nascimento, D. M., Almeida, J. S., Dias, A. F., Figueirêdo, M. C. B., Morais, J. P. S., Feitosa, J. P. A., et al. (2014). A novel green approach for the preparation of cellulose nanowhiskers from white coir. Carbohydrate Polymers, 110, 456-463.

Ojagh, S. M., Rezaei, M., Razavi, S. H., \& Hosseini, S. M. H. (2010). Development and evaluation of a novel biodegradable film made from chitosan and cinnamon essential oil with low affinity toward water. Food Chemistry, 122, 161-166.
Olivato, J. B., Grossmann, M. V. E., Bilck, A. P., \& Yamashita, F. (2012). Effect of organic acids as additives on the performance of thermoplastic starch/polyester blown films. Carbohydrate Polymers, 90, 159-164.

Olsson, E., Hedenqvist, M. S., Johansson, C., \& Järnström, L. (2013). Influence of citric acid and curing on moisture sorption: diffusion and permeability of starch films. Carbohydrate Polymers, 94, 765-772.

Olsson, E., Menzel, C., Johansson, C., Andersson, R., Koch, K., \& Järnström, L. (2013). The effect of $\mathrm{pH}$ on hydrolysis, cross-linking and barrier properties of starch barriers containing citric acid. Carbohydrate Polymers, 98, 1505-1513.

Ortega-Toro, R., Collazo-Bigliardi, S., Talens, P., \& Chiralt, A. (2016). Influence of citric acid on the properties and stability of starch-polycaprolactone based films. Journal of Applied Polymer Science, 133, 42220.

Peng, F., Bian, J., Peng, P., Guan, Y., Xu, F., \& Sun, R. C. (2012). Fractional separation and structural features of hemicelluloses from sweet sorghum leaves. Bioresources, 7, 4744-4759.

Peng, H., Hu, Z., Yu, Z., Zhang, J., Liu, Y., Wan, Y., et al. (2012). Fractionation and thermal characterization of hemicelluloses from bamboo (Phyllostachys pubescens Mazel) culm. Bioresources, 7, 374-390.

Qi, H., Cai, J., Zhang, L., \& Kuga, S. (2009). Properties of films composed of cellulose nanowhiskers and a cellulose matrix regenerated from alkali/urea solution. Biomacromolecules, 10, 1597-1602.

Reddy, N., \& Yang, Y. (2010). Citric acid cross-linking of starch films. Food Chemistry, 118, 702-711.

Reddy, N., Jiang, Q., \& Yang, Y. (2012). Preparation and properties of peanut protein films crosslinked with citric acid. Industrial Crops and Products, 39, 26-30.

Rhim, J. W., \& Ng, P. K. W. (2007). Natural biopolymer-based nanocomposite films for packaging applications. Critical Reviews in Food Science and Nutrition, 47, 411-433.

Robert, P., Marquis, M., Barron, C., Guillon, F., \& Saulnier, L. (2005). FT-IR investigation of cell wall polysaccharides from cereal grains. Arabinoxylan Infrared assignment. Journal of Agricultural and Food Chemistry, 53, 7014-7018.

Roy, S., Gennadios, A., Weller, C. L., \& Testin, R. F. (2000). Water vapor transport parameters of a cast wheat gluten film. Industrial Crops and Products, 11, 43-50.

Salmah, H., Romisuhani, A., \& Akmal, H. (2011). Properties of low-density polyethylene/palm kernel shell composites: Effect of polyethylene co-acrylic acid. Journal of Thermoplastic Composite Material, 26, 3-15.

Sebti, I., Delves-Broughton, J., \& Coma, V. (2003). Physicochemical properties and bioactivity of nisin-containing cross-linked hydroxypropylmethylcellulose films. Journal of Agricultural and Food Chemistry, 51, 6468-6474.

Shi, R., Zhang, Z., Liu, Q., Han, Y., Zhang, L., Chen, D., et al. (2007). Characterization of citric acid/glycerol co-plasticized thermoplastic starch prepared by melt blending. Carbohydrate Polymers, 69, 748-755.

Shi, R., Bi, J., Zhang, Z., Zhu, A., Chen, D., Zhou, X., et al. (2008). The effect of citric acid on the structural properties and cytotoxicity of the polyvinyl alcohol/starch films when molding at high temperature. Carbohydrate Polymers, 74, 763-770.

TAPPI. (2004). T 222 om-02. Acid-insoluble lignin in wood and pulp.

TAPPI. (2009). T $203 \mathrm{~cm}$-99. Alpha-, beta- and gamma-cellulose in pulp.

Tajeddin, B., Rahman, R. A., \& Abdulah, L. C. (2010). The effect of polyethylene glycol on the characteristics of kenaf cellulose/low-density polyethylene biocomposites. International Journal of Biological Macromolecules, 47, 292-297.

Thomsen, M. (2005). Complex media from processing of agricultural crops for microbial fermentation. Applied Microbiology and Biotechnology, 68, 598-606.

Toole, G. A., Le Gall, G., Colquhoun, I. J., Drea, S., Opanowicz, M., Bedö, Z., et al. (2012). Spectroscopic analysis of diversity in the spatial distribution of arabinoxylan structures in endosperm cell walls of cereal species in the HEALTHGRAIN diversity collection. Journal of Cereal Science, 56, 134-141.

WASDE. (2016). World agricultural supply and demand estimates. WASDE -551. [(March 9 2016) Available at http://www.usda.gov/oce/commodity/wasde/ latest.pdf. accessed 06 April 2016]

Wang, S., Ren, J., Li, W., Sun, R., \& Liu, S. (2014). Properties of polyvinyl alcohol/xylan composite films with citric acid. Carbohydrate Polymers, 103, 94-99.

Yao, W., Wang, B., Ye, T., \& Yang, Y. (2013). Durable press finishing of cotton fabrics with citric acid: enhancement of whiteness and wrinkle recovery by polyol extenders. Industrial and Engineering Chemistry Research, 52, 16118-16127.

Zhang, P., \& Whistler, R. L. (2004). Mechanical properties and water vapor permeability of thin film from corn hull arabinoxylan. Journal of Applied Polymer Science, 93, 2896-2902.

Zhang, B.-Y., Hu, J.-S., Jia, Y.-G., \& Du, B.-G. (2003). Side-chain cholesteric liquid crystalline elastomers derived from nematic bis-olefinic crosslinking units. Macromolecular Chemistry and Physics, 204, 2123-2129. 